\title{
TINGKAT KESUKARAN SOAL TES BERPIKIR TINGKAT TINGGI BERBASIS KEARIFAN LOKAL PADA MATERI KEANEKARAGAMAN HAYATI DI SMA
}

\author{
Khairil Hadi $^{1)}$, Dazrullisa ${ }^{2)}$, Binari Manurung ${ }^{3)}$, Hasruddin ${ }^{4)}$ \\ ${ }^{1)}$ Program Studi Pendidikan Biologi STKIP Bina Bangsa Meulaboh, Aceh \\ email: herilbio@yahoo.co.id \\ 2) Program Studi Pendidikan Matematika STKIP Bina Bangsa Meulaboh, Aceh \\ email: dazrullisa@yahoo.co.id \\ ${ }^{3)}$ Program Studi Pendidikan Biologi Universitas Negeri Medan, Sumatera Utara \\ email: binari44@hotmail.com \\ 4) Program Studi Pendidikan Biologi Universitas Negeri Medan, Sumatera Utara \\ email: hasruddin_lbsmdn@yahoo.com
}

\begin{abstract}
ABSTRAK: Soal tes merupakan alat yang diperuntukkan untuk mengukur dan atau mengetahui keberhasilan proses pembelajaran. Soal yang baik akan menghasilkan hasil pengukuran yang tepat dan sebaliknya soal yang tidak baik akan menghasilkan hasil pengukuran yang kurang tepat dari tujuan yang telah ditentukan. Tujuan penelitian adalah untuk mengetahui tingkat kesukaran soal tes berpikir tingkat tinggi berbasis kearifan lokal pada materi keanekaragaman hayati. Penelitian ini menggunakan pendekatan kuantitatif dan sedangkan jenis penelitian adalah deskriptif. Populasi dalam penelitian ini adalah seluruh siswa kelas $\mathrm{X}$ dari 5 sekolah menengah atas di kabupaten Aceh Barat yang berjumlah 284 siswa. Sampel yang digunakan dalam penelitian sebanyak 111 yang berasal dari kelas X sains. Sampel ditentukan dengan menggunakan teknik pengambilan sampel random sampling. Instrumen yang digunakan adalah lembar tes pilihan ganda sebanyak 20 soal. Teknik analisis data yang digunakan adalah uji tingkat kesukaran soal. Setelah dilakukan analisis data, kemudian data di intepretasikan dalam bentuk kata-kata, yaitu sukar $(\mathrm{P}<0,3)$, Sedang $(0,3 \leq \mathrm{p} \leq 0,7)$, dan mudah $(\mathrm{P}>$ 0,7). Hasil analisis data menunjukkan bahwa soal yang berkriteri sukar 5 soal, berkriteria sedang 10 soal, dan berkriteria mudah 5 soal dengan perbandingan persentase 25:50:25. Hasil penelitian juga menunjukkan bahwa level taksonomi bloom tidak berpengaruh terhadap kategori soal tersebut mudah, sukar, dan sedang.
\end{abstract}

Kata Kunci: Tingkat kesukaran, soal tes berpikir tingkat tinggi, kearifan lokal, keanekaragaman hayati.

\section{ABSTRACT:}

Test is about is a for measuring and or knowing success learning. About good result and about exact measurements and is not will produce a bad result of measuring the point of specified.Research objectives is to know the level hardship test think about a high degree of matter based local knowledge biodiversity.Research used the quantitative and while the types is descriptive research.It is a whole population in research students $\mathrm{X}$ from 5 senior high school in the district of aceh students were 284 west. Sample used in research 111 derived from a class $\mathrm{x}$ science .Sample is determined by using a technique the sample collection random sampling.An instrument that is used is sheets of as many as 20 about the average multiple choice test .The technique of data analysis will be a 
very hard test that is used is the level of about .Following the completion of data analysis, then the data in search in the form of words, that is very difficult to play ( $\mathrm{P}<$ $0,3)$, temperate $(0,3 \leq p \leq 0,7)$, and easily $(P>0,7)$. The analysis of the data shows that about berkriteri difficult 5, about berkriteria, 10 was about and berkriteria 5 easy by comparison with the percentage 25: 50: 25. The research also shows that the level of taxonomic bloom will not affect, easy categories that situation, difficult and was.

Keyword: The trouble, think about the test high level, local knowledge, biodiversity

\section{PENDAHULUAN}

Keberhasilan proses pembelajaran diukur menggunakan instrumen penilaian. Instrumen penilaian merupakan alat ukur yang bertujuan untuk mengukur pengetahuan siswa terhadap materi yang telah diajarkan oleh guru sebagai sebuah keputusan terkait kemampuan siswa. Basuki (2015) menyatakan bahwa suatu kegiatan identifikasi untuk melihat ketercapaian suatu program yang telah dirancang atau belum disebut sebagai evaluasi. Instrumen dan ataupun alat ukur yang digunakan dalam pembelajaran dapat dilakukan dengan lembar tes. Lembar tes merupakan suatu alat ukur berisikan soal (pertanyaan) yang diberikan kepada suatu individu sebagai tujuan untuk mengetahui tingkat pemahaman suatu individu atas apa yang telah dipelajari.

Proses evaluasi atau penilaian pada Kurikulum 2013 terhadap proses pembelajaran meliputi sikap, pengetahuan, dan keterampilan harus dilaksanakan oleh guru. Berbicara ranah kognitif (pengetahuan) tidak terlepas dari kemampuan berpikir menurut taksonomi bloom. Menurut taksonomi bloom revisi proses berpikir dkategorikan ke enam tingkatan, yaitu pengetahuan (cognitif 1), pemahaman (cognitif 2), sintesis (cognitif 3), analisis (cognitif 4), evaluasi (cognitif 5) dan kreasi (cognitif 6). Selanjutnya, dari ke enam tingkatan berpikir tersebut dipisahkan menjadi dua kategori, yaitu berpikir tingkat rendah $(\mathrm{C} 1, \mathrm{C} 2, \mathrm{C} 3)$ dan berpikir tingkat tinggi $(\mathrm{C} 4, \mathrm{C} 5, \mathrm{C} 6)$.

Hasil tes PISA menunjukkan bahwa kemampuan berpikir tingkat tinggi siswa Indonesia masih tergolong rendah. Siswa Indonesia hanya mampu berada pada peringkat 64 dari 65 negara pada tahun 2012 dan mampu berada pada peringkat 62 dari 70 negara pada tahun 2015 (OECD 2012 \& OECD 2015). Hadi, K (2018) menyatakan 
bahwa salah satu penyebab hal ini terjadi dikarenakan disekolah guru kurang melatih keterampilan berpikir siswa. Maka oleh sebab itu, guru perlu pengetahuan yang baik dalam merumuskan soal penilaian, salah satunya dalam penyusunan soal berpikir tingkat tinggi. Proses kegiatan penilaian berpikir tingkat tinggi yang dilakukan disekolah merupakan bagian dari hasil belajar (Mardapi, 2012).

Indikator untuk mengukur kemampuan berpikir tingkat tinggi menurut Krathwohl (2002) yaitu: (1) Menganalisis, yaitu (a) Melakukan analisis terhadap suatu informasi dan kemudian memisahkan informasi tersebut kebeberapa bagian sebagai dasar untuk mengetahui pola atau hubungan, (b) Mampu mengenal dan membedakan sebuah skenario ditinjau dari penyebab dan akibat, dan (c) Mampu menyusun pertanyaanpertanyaan.; (2) Mengevaluasi, yaitu (a) pemberian nilai dengan menggunakan metodologi yang sesuai dengan kriteri untuk memastikan nilai efektivitas dan manfaat dari sebuah solusi dan gagasan, (b) Menyusun hipotesa, melakukan kritik dan dilakukan pengujian, (c) Suatu pernyataan dapat diterima atau ditolak dengan mengacu kepada kriteria yang sudah ditentukan.; (3) Mengkreasi, yaitu (a) Dapat mengeneralisasikan suatu ide atau cara pandang terhadap sesuatu, (b) Menyelesaikan masalah melalui perancangan cara, (c) Pengorganisasian unsur atau bagian tertentu menjadi sebuah struktur baru.

Penerapan pertanyaan berpikir tingkat tinggi bertujuan untuk melatih siswa agar dapat berpikir secara terbuka terhadap permasalahan-permasalahan yang diajukan sehingga mendapatkan jawaban dan atau solusi dari permasalahan tersebut. Bernett \& Francis (2011) mengemukakan bahwa untuk melatih siswa berpikir secara mendalam terhadap materi pembelajaran dapat dilakukan dengan memberikan pertanyaan dengan kriteria berpikir tingkat tinggi. Siswa dapat menemukan cara baru dalam menyelesaikan permasalahan melalui kemampuan berpikir tingkat tinggi (Yee, 2015).

Seiring dengan perkembangan zaman, ide-ide terbaru dalam melakukan inovasi muncul untuk dirumuskan dan diterapkan termasuk dalam perumusan soal tes. Agar soal tes dapat dipahami dengan mudah oleh 
peserta didik dapat dilakukan dengan cara merumuskan pertanyaanpertanyaan sesuai kehidupan nyata peserta didik. Kehidupan nyata tersebut dapat disebut kearifan lokal. Nadiroh, A \& Sutanto, A. (2012) menyatakan agar pelaksanaan proses pembelajaran efektif perlu penerapan budaya lokal dalam pembelajaran. Fenomena budaya lokal yang sesuai dengan pengetahuan mereka sebelumnya membantu mereka membangun pengetahuan baru (Suardana, I, N et all. 2018).

Soal tes berpikir tingkat tinggi berbasis kearifan lokal yang digunakan pada penelitian ini disusun dengan bentuk tes pilihan ganda, karena banyak digunakan dalam pengukuran hasil belajar siswa baik dalam ujian tengah semester, ujian akhir semester, dan bahka ujian nasional. Soal tes berbentuk pilihan ganda merupakan lembar yang berisi pertanyaan dan alternatif jawaban yang mengcakup jawaban benar dan jawaban pengecoh. Yuniar, M., Rakhmat, C., \& Saepulrohman, A ( 2015) menyatakan bahwa soal pilihan ganda mempunyai kelibihan yaitu soal yang diuji memiliki materi dengan cakupan yang luas, soal pilihan ganda memiliki tingkan validitas dan reliabilitas yang tinggi dari pada soal essay, soal pilihan ganda lebih mudah mengerjakannya, aspek kognitif dapat diukur oleh guru, bersifat objektif dan melakukan penilaian mudah dan cepat.

\section{METODE PENELITIAN}

\section{Pendekatan dan Jenis Penelitian}

Pendekatan yang digunakan dalam penelitian ini adalah pendekatan kuantitatif dan sedangkan jenis penilitian adalah deskriptif. Pendekatan kuantitatif digunakan dalam penelitian ini guna menguji tingkat kesukaran dari hasil jawaban siswa terhadap soal berpikir tingkat tinggi pada materi keanekaragaman hayati berbasis kerifan lokal. Sedangkan jenis penelitian deskriptif digunakan dengan tujuan untuk menggambarkan hasil temuantemuan dari hasil telaah tingkat kesukaran yang kemudian di interpretasikan dalam bentuk kata.

\section{Populasi dan Sampel}

Penelitian ini dilaksanakan di sekolah menengah atas (SMA) Kabupaten Aceh Barat pada kelas X bidang sains yang terdiri dari 5 sekolah . Populasi dalam penelitian ini berjumlah 284 siswa dan sampel yang digunakan berjumlah 111 siswa. Teknik pengambilan sampel yang digunakan 
dalam penelitian ini, yaitu teknik random sampling.

Tabel 1 Frekuensi populasi dan sampel penelitian

\begin{tabular}{|c|c|c|c|c|}
\hline \multirow{2}{*}{ Sekolah } & \multicolumn{2}{|c|}{ Populasi } & \multicolumn{2}{|c|}{ Sampel } \\
\hline & Kelas & frekuensi & Kelas & frekuensi \\
\hline \multirow{3}{*}{ Sekolah A } & $\mathrm{X}_{1}$ Sains & 27 & \multirow{3}{*}{$\mathrm{X}_{1}$ Sains } & \multirow{3}{*}{27} \\
\hline & $\mathrm{X}_{2}$ Sains & 25 & & \\
\hline & $\mathrm{X}_{3}$ Sains & 27 & & \\
\hline \multirow{2}{*}{ Sekolah B } & $\mathrm{X}_{1}$ Sains & 20 & \multirow{2}{*}{$\mathrm{X}_{2}$ Sains } & \multirow{2}{*}{20} \\
\hline & $\mathrm{X}_{2}$ Sains & 20 & & \\
\hline \multirow{3}{*}{ Sekolah C } & $\mathrm{X}_{1}$ Sains & 20 & \multirow{3}{*}{$\mathrm{X}_{2}$ Sains } & \multirow{3}{*}{20} \\
\hline & $\mathrm{X}_{2}$ Sains & 20 & & \\
\hline & $\mathrm{X}_{3}$ Sains & 19 & & \\
\hline \multirow{3}{*}{ Sekolah D } & $\mathrm{X}_{1}$ Sains & 21 & \multirow{3}{*}{ X3 Sains } & \multirow{3}{*}{24} \\
\hline & $\mathrm{X}_{2}$ Sains & 23 & & \\
\hline & $\mathrm{X}_{3}$ Sains & 24 & & \\
\hline \multirow{2}{*}{ Sekolah E } & $\mathrm{X}_{1}$ Sains & 20 & \multirow{2}{*}{$\mathrm{X}_{1}$ Sains } & \multirow{2}{*}{20} \\
\hline & $\mathrm{X}_{2}$ Sains & 18 & & \\
\hline 5 Sekolah & Jumlah & 284 & Jumlah & 111 \\
\hline
\end{tabular}

\section{Instrumen Penelitian}

Instrumen yang digunakan dalam penelitian ini adalah lembar tes berpikir tingkat tinggi pada materi keanekaragaman hayati berbasis kearifan lokal yang berjumlah sejumlah 20 soal.

Tabel 2. Kisi-kisi Soal Tes Berpikir Tingkat Tinggi

\begin{tabular}{|c|c|c|c|}
\hline Materi & Indikator & $\begin{array}{c}\text { Nomor } \\
\text { Soal }\end{array}$ & Kriteria \\
\hline \multirow{13}{*}{$\begin{array}{c}\text { Keanekaragaman } \\
\text { Hayati }\end{array}$} & \multirow{4}{*}{$\begin{array}{l}\text { Mengidentifikasi } \\
\text { keanekaragaman hayati } \\
\text { Indonesia dan pesebaran flora } \\
\text { dan fauna Indonesia }\end{array}$} & 1 & $\mathrm{C} 5$ \\
\hline & & 8 & $\mathrm{C} 4$ \\
\hline & & 13 & C6 \\
\hline & & 19 & C5 \\
\hline & \multirow{4}{*}{$\begin{array}{l}\text { Menyimpulkan perbedaan serta } \\
\text { contoh dari keanekaragaman } \\
\text { tingkat gen, jenis, dan ekosistem, } \\
\text { yang terdapat Aceh khususnya } \\
\text { dan Indonesia umumnya }\end{array}$} & 5 & $\mathrm{C} 4$ \\
\hline & & 14 & $\mathrm{C} 4$ \\
\hline & & 6 & $\mathrm{C} 5$ \\
\hline & & 18 & $\mathrm{C} 4$ \\
\hline & \multirow{4}{*}{$\begin{array}{l}\text { Menganalisis kerusakan } \\
\text { keanekaragaman hayati dan } \\
\text { konservasi keanekaragaman } \\
\text { hayati untuk keberlangsungan } \\
\text { kehidupan berkelanjutan }\end{array}$} & 2 & C6 \\
\hline & & 7 & $\mathrm{C} 4$ \\
\hline & & 17 & $\mathrm{C} 5$ \\
\hline & & 20 & $\mathrm{C} 4$ \\
\hline & Menyimpulkan nilai-nilai & 16 & $\mathrm{C} 4$ \\
\hline
\end{tabular}




\begin{tabular}{lcc} 
keanekaragaman hayati & 4 & C5 \\
\cline { 2 - 3 } berdasarkan tempat & 9 & C6 \\
\cline { 2 - 3 } & 10 & $\mathrm{C} 5$ \\
\hline \multirow{3}{*}{ Menyimpulkan sistem klasifikasi } & 3 & $\mathrm{C} 6$ \\
\cline { 2 - 3 } & 11 & $\mathrm{C} 5$ \\
\cline { 2 - 3 } & 12 & $\mathrm{C} 5$ \\
\hline
\end{tabular}

\section{Teknik Analisis data}

Data dalam penelitian ini dianaisis menggunakan statistik uji tingkat kesukaran. Setelah data dianalisis, kemudian data di konversikan (tabel 3)

$\mathrm{P}=\frac{\mathrm{B}}{\mathrm{JS}}$

Keterangan: P : Indeks Kesukaran

B : Banyaknya siswa yang menjawab soal denagan betul

JS : Jumlah seluruh siswa peserta tes

Tabel 3. Konversi Nilai Daya Beda

\begin{tabular}{cc}
\hline Koefisien & Kategori \\
\hline $\mathrm{P}<0,3$ & Sukar \\
$0,3 \leq \mathrm{p} \leq 0,7$ & Sedang \\
$\mathrm{P}>0,7$ & Mudah \\
\hline & (Mardapi, 2012)
\end{tabular}

\section{HASIL DAN PEMBAHASAN}

Tabel 4. Hasil uji tingkat kesukaran Soal Tes Berpikir Tingkat Tinggi Berbasis kearifan Lokal

\begin{tabular}{|c|c|c|}
\hline $\begin{array}{c}\text { No } \\
\text { Soal }\end{array}$ & Tingkat Kesukaran & Kategori \\
\hline 1 & 0,705 & Mudah \\
\hline 2 & 0,714 & Mudah \\
\hline 3 & 0,303 & Sedang \\
\hline 4 & 0,303 & Sedang \\
\hline 5 & 0,303 & Sedang \\
\hline 6 & 0,134 & Sukar \\
\hline 7 & 0,143 & Sukar \\
\hline 8 & 0,714 & Mudah \\
\hline 9 & 0,223 & Sukar \\
\hline 10 & 0,714 & Mudah \\
\hline 11 & 0,303 & Sedang \\
\hline
\end{tabular}




\begin{tabular}{|l|c|c|}
\hline 12 & 0,303 & Sedang \\
\hline 13 & 0,705 & Mudah \\
\hline 14 & 0,313 & Sedang \\
\hline 15 & 0,312 & Sedang \\
\hline 16 & 0,313 & Sedang \\
\hline 17 & 0,303 & Sedang \\
\hline 18 & 0,312 & Sedang \\
\hline 19 & 0,179 & Sukar \\
\hline 20 & 0,16 & Sukar \\
\hline
\end{tabular}

Tabel 5. Rekapitulasi Tingkat Kesukaran Jumlah Soal

\begin{tabular}{|c|c|c|}
\hline Kategori & Jumlah Soal & Persentase (\%) \\
\hline Sukar & 5 & 25 \\
\hline Sedang & 10 & 50 \\
\hline Mudah & 5 & 25 \\
\hline
\end{tabular}

\section{PEMBAHASAN}

Soal tes berpikir tingkat tinggi berbasis kearifan lokal dalam penelitian ini merupakan soal hasil pengembangan peneliti pada materi keanekaragaman hayati. Pengembangan soal tes dalam penelitian ini dikembangkan melalui tahapan-tahapan, yaitu analisis outcome materi keanekaragaman hayati, analisis kearifan lokal yang mendukung materi keanekaragaman hayati, analisis berpikir menurut taksonomi bloom revisi, dan perumusan soal berpikir tingkat berbasis kearifan lokal pada materi keanekaragaman hayati. Untuk mencapai kesempurnaan soal hasil pengembangan ini, telah dilakukan beberapa uji seperti validasi ahli dan kesesuaian kata kerja operasional taksonomi bloom pada penelitian- penelitian sebelumnya. Maka pada tulisan ini, peneliti mengususkan tulisan ini pada uji tingkat kesukaran soal tes setelah dilakukan uji coba kepada 111 siswa yang berasal dari 5 sekolah di Kabupaten Aceh Barat Provinsi Aceh.

Hasil analisis data (tabel 4 \&5) menunjukkan bahwa soal tes berpikir tingkat tinggi berbasis kearifan lokal pada materi keanekaragaman hayati diketahui dengan perbandingan 1:2:1 atau 25\% (5) : 50\% (10) : 25\%(5) dari 20 soal. Hasil penelitian ini sesuai dengan yang diungkapkan Amelia, M., A., (2012) bahwa distribusi tingkat kesukaran, dari 20 yang digunakan adalah: $25 \%$ mudah (5 soal), $50 \%$ sedang (10 soal), dan $25 \%$ sukar (5 soal). Sudijono (2009) menyatakan bahwa soal yang memiliki tingkat 
kesukaran cukup atau sedang dan atau soal yang tidak terlalu mudah atau sukar merupakan butir soal yang baik.

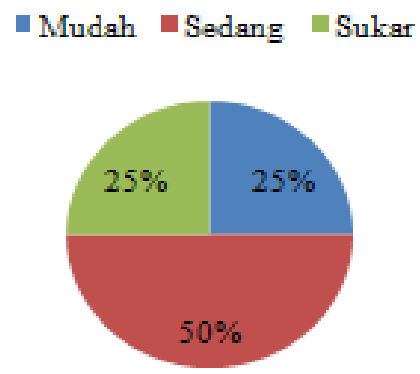

Gambar 1. Perbandingan Tingkat Kesukaran Soal Berpikir Tingkat Tinggi

Berbicara mengenai berpikir tingkat tinggi tidak terlepas dari kemampuan berpikir yang dirumuskan di dalam Taksonomi Bloom. Dalam perumusan soal dalam penelitian ini, kata kerja operasional yang digunakan disaji pada tabel 6. Krathworl \& Anderson (2001) menyatakan bahwa kata kerja operasional pada $\mathrm{C} 4$, yaitu menganalisis, menyimpulkan, menentukan, membandingkan, dan mengoreksi., pada C5, yaitu mengkritisi dan memprediksi., dan pada C6, yaitu melakukan, membuat, dan merancang.

Tabel 6. Penggunaan kata kerja pengembangan soal tes Berpikir Tingkat Tinggi

Berbasis Kearifan lokal dengan Taksonomi Bloom Revisi

\begin{tabular}{|l|l|l|}
\hline No & Berpikir Tingkat Tinggi & Kata kerja Operasional yang digunakan \\
\hline 1 & Analisis & 1. Menegaskan \\
& & 2. Menyimpulkan \\
& & 3. Menyeleksi \\
& & 4. Menelaah \\
\hline 2 & Evaluasi & $\begin{array}{l}\text { 1. Memilih } \\
\end{array}$ \\
& & 2. Memprediksi \\
& & 3. Membandingkan \\
& & 5. Memperjelas \\
\hline 3 & Create & 1. Mengkategorikan \\
& & 2. Menghubungkan \\
\hline
\end{tabular}

Dilihat dari soal yang berkategori sukar pada no 6 (C5), 7 (C4), 9 (C6), 19 ( C5), dan 20 (C4) diketahui bahwa, soal sesuai level taksonomi bloom tidak berpengaruh terhadap kategori soal tersebut mudah, sukar, dan sedang. Menurut Gais, Z (2017) bahwa penyebab siswa keliru dalam menyelesiakan soal high order thinking disebabkan siswa kurang teliti dalam menjawab, siswa memiliki kemampuan awal yang rendah, siswa tidak menerima pembelajaran secara menyeluruh, siswa kurang memahami 
soal, siswa belum lengkap membaca soal serta masih minimnya perhatian orang tua.

Melatih keterampilan berpikir siswa dapat ditingkatkan melalui tahapan-tahapan pelaksanaan proses pembelajaran termasuk didalamnya proses penilaian. Untuk mengetahui kemampuan berpikir tingkat tinggi siswa, seorang guru harus memiliki kemampuan dalam menyusun soal bercirikan keterampilan berpikir tingkat tinggi. Adapun langkah-langkah yang dapat dilakukan dalam penyusunan soal berkriteria berpikir tingkat tinggi meliputi (1) analisis outcome materi pelajaran, (2) penentuan indikator, (3) penyusunan tujuan, (4) analisis kata kerja operasional berpikir tingkat tinggi taksonomi , (5) penyusunan kisi-kisi soal, dan (6) perumusan soal berpikir tingkat tinggi.

\section{KESIMPULAN}

Kesimpulan dari penelitian ini yaitu soal tes berpikir tingkat tinggi berbasis kearifan lokal pada materi keanekaragaman hayati sangat baik dimana perbandingan soalnya atau tingkat kesukarannya berbanding 1:2:1 (25\%:50\%:25\%). Namun penelitian ini perlu dilakukan uji lanjut, yaitu uji daya beda soal.

\section{UCAPAN TERIMAKASIH}

Ucapan terimakasih kami hantarkan kepada kementerian riset, teknologi, dan pendidikan tinggi Republik Indonesia yang telah mendanai penelitian ini pada tahun 2019.

\section{DAFTAR PUSTAKA}

Amelia, M., A., (2016). Analisis Soal Tes Hasil Belajar High Order Thinking Skills (HOTS) Matematika Materi Pecahan Untuk Kelas 5 Sekolah Dasar. Jurnal Penelitian (Edisi Khusus PGSD), Volume 20, No 2, hal 123-131.

Barnett, J. E. \& Francis, A. L. (2011). Using higher order thinking questions to foster Critical Thinking: a classroom study. Educational Psychology: An International Journal of Experimental Educational Psychology, 32(2), 201-211.

Basuki, I. dkk.. (2015). Assmen Pembelajaran.Bandung : Remaja Rosdakarya

Gais,Zakkina, dkk. (2017). Analisis kemampuan siswa dalam menyelesaikan soal high. Mosharafa, 6(2), 255-266.

Hadi K, Dazrullisa, Manurung B., Hasruddin. 2018. Development of biological teaching materials based on local wisdom integrated 
character education and problem based learning models for senior high school in aceh baratIndonesia. International Journal of Research and Review. 5(9):106-115.

Joyce, Bruce. dkk.. (2009). Model of Teaching Model-model Pengajaran. Yogyakarta: Pustaka Pelajar

Krathwohl, D. R. 2002. A revision of Bloom's Taxonomy: an overview - Theory Into Practice, College of Education, The Ohio State University Learning Domains or Bloom's Taxonomy: The Three Types of Learning, tersedia di www.nwlink.com/ donclark/hrd/b loom.htm

Mardapi, D. (2012). Pengukuran, penilaian dan evaluasi pendidikan. Yogyakarta: Nuha Medika.

Nadiroh, A \& Sutanto, A. 2012. Penerapan Model Pembelajaran Berbasis Lingkungan Untuk Mengembangkan Keterampilan Proses Sains Dan Meningkatkan Hasil Belajar Kognitif Pada Siswa Kelas X Sma Muhammadiyah 1 Metro Tahun Pelajaran 2011/2012. Bioedukasi, Vol 3, No 2.

OECD. 2012. PISA 2012 Results in Focus What 15 Year Olds Know and What They Can Do with What They Know. OECD

OECD (2015). Programme for International Student Assessment (PISA). Diakses dari
http://www.oecd.org/pisa/PISA2015-Indonesia.pdf

Sudijono, A. (2009). Pengantar Evaluasi Pendidikan. Jakarta : Rajawali Pers.

Suardana, I, N., Redhana, I, W., Sudiatmika A, A, I, A, Rai et all. 2018. Students' Critical Thinking Skills in Chemistry Learning Using Local Culture-Based 7E Learning Cycle Model. International Journal of Intruction. Vol. 11, No. 2, pp 400-412.

Yee. (2015). The Effectiveness of Higher Order Thinking Skills for Generating Idea among Technical Students. Recent Advances in Educational Technologies, 1(1), 223-241.

Yuniar, M., Rakhmat, C., \& Saepulrohman, A ( 2015). Analisis Hots (High Order Thinking Skills) Pada Soal Objektif Tes Dalam Mata Pelajaran Ilmu Pengetahuan Sosial (IPS) Kelas V SD Negeri 7 Ciamis. Jurusan Pendidikan Guru Sekolah Dasar, Fakultas Ilmu Pendidikan, Universitas Pendidikan Indonesia, 